\title{
LANJUT USIA (LANSIA) PEDULI MASA DEPAN DI DAERAH ISTIMEWA YOGYAKARTA
}

\author{
Oleh:
}

\author{
Nurul Khotimah' ${ }^{1}$, Gunardo RB ${ }^{1}$, Anik Ghufron ${ }^{1}$, Sri Sugiharti ${ }^{2}$, dan Kanthi Aryekti ${ }^{2}$ \\ ${ }^{1}$ LPPM Universitas Negeri Yogyakarta \\ ${ }^{2}$ BKKBN Daerah Istimewa Yogyakarta \\ nurul khotimah79@yahoo.co.id
}

\begin{abstract}
Abstrak
Penelitian ini bertujuan mengetahui: (1) kondisi lansia di Daerah Istimewa Yogyakarta (DIY) berdasarkan lima dimensi, yaitu fisik, psikologis, mental, spiritual, sosial kemasyarakatan, dan pengembangan potensi. (2) tingkat peduli masa depan lansia di DIY. Sampel penelitian ini ditentukan secara purposive sampling, dengan pertimbangan wilayah yang berpartisipasi dalam penilaian lomba kelompok Bina Keluarga Lansia (BKL) Tahun 2014. Pengumpulan data melalui observasi, wawancara, dan dokumentasi. Analisis data dilakukan secara deskriptif kuantitatif. Hasil penelitian: (1) Kondisi lansia di DIY: (a) dimensi fisik dan psikologis termasuk kategori sedang, baik peserta BKL maupun non peserta BKL. Kondisi ini dijumpai pada semua kabupaten/kota, kecuali peserta BKL Kabupaten Gunungkidul termasuk kategori tinggi, (b) dimensi mental spiritual, sosial kemasyarakatan, dan pengembangan potensi termasuk kategori tinggi, baik lansia peserta BKL maupun non peserta BKL, pada semua kabupaten/kota DIY. (2) Tingkat kepedulian lansia pada masa depannya berada pada kategori tinggi, baik peserta BKL maupun non peserta BKL. Tingkat peduli masa depan lansia di kabupaten/kota juga berada pada kategori tinggi, kecuali Kota Yogyakarta (lansia peserta BKL) dan Kabupaten Kulonprogo (lansia non peserta BKL) kategori sedang.
\end{abstract}

Kata kunci: lansia, peduli masa depan, Daerah Istimewa Yogyakarta

\begin{abstract}
This research aims at investigating: (1) the condition of the elderly in the Yogyakarta Special Region (DIY) based on five dimensions: physical, psychological, mental, spiritual, social, and potential of development. (2) the level of future care of the elderly in DIY. The research sample was determined using purposive sampling technique, by considering the regions participating in the assessment of groups competition of Elderly Family Development (EFD) 2014. The data were collected through observations, interviews, and documentations. The data were analyzed using descriptive qualitative method. The results are: (1) elderly condition in DIY: (a) Physical and psychological dimensions belong to medium category for both EFD participants and non participants. This condition is found in all districts/cities, except EFD participants in Gunungkidul that belong to high category. (b) mental and spiritual dimensions, social, and development potential are high, both EFD participants and non participants, in all districts/cities in DIY. (2) The level of concern for the elderly in the future stays at high category. The level of future care of the elderly in the district/city are also in the high category, except the city of Yogyakarta (EFD participants) and Kulon Progo Regency (non participants EFD) which belong to a medium category.
\end{abstract}

Keywords: ederly, care future, Yogyakarta Special Region 


\section{PENDAHULUAN}

Keberadaan lanjut usia (lansia) memegang peranan penting bagi pembangunan Indonesia. Hal ini mengingat bahwa salah satu indikator keberhasilan pembangunan adalah semakin meningkatnya usia harapan hidup. Dengan semakin meningkatnya usia harapan hidup maka menyebabkan jumlah penduduk lansia semakin besar. Penduduk lansia sebagai modal pemerintah untuk meningkatkan Indeks Pembangunan Manusia (IPM) serta menuntaskan target dan sasaran Millenium Development Goals (MDGs) pada tahun 2015. Undang-Undang Republik Indonesia No. 13 Tahun 1998 tentang kesejahteraan lansia mengemukakan bahwa lansia adalah seseorang yang mencapai usia 60 tahun ke atas.

Jumlah penduduk lansia di Indonesia terbesar keempat di dunia setelah Cina, India, dan Jepang. Berdasarkan proyeksi penduduk tahun 2010-2035, jumlah penduduk lansia di Indonesia tahun 2014 diperkirakan sebesar 20,8 juta jiwa (BKKBN, 2014). Di Daerah Istimewa Yogyakarta, jumlah penduduk lansia tahun 2013 sebesar 13,56\% dari keseluruhan penduduk (BPS, 2013). Besarnya jumlah penduduk lansia di Daerah Istimewa Yogyakarta perlu menjadi perhatian tersendiri, mengingat di satu sisi semakin meningkatnya penduduk lansia berarti kualitas hidup semakin baik seiring semakin baiknya akses untuk mendapatkan fasilitas kesehatan sehingga usia harapan hidup meningkat. Penanganan kesehatan umum lansia sudah dilakukan Pemerintah melalui puskesmas dan posyandu lansia. Namun demikian, di sisi lain penduduk lansia menghadapi berbagai perubahan dalam hidupnya, yaitu kemunduran kondisi kesehatan fisik dan psikis yang dapat mempengaruhi kondisi sosial ekonomi, sehingga secara perlahan akan mengalami ketergantungan kepada orang lain.

Beberapa permasalahan umum penduduk lansia, antara lain: (1) keadaan fisik lemah dan tidak berdaya, (2) status ekonomi terancam, (3) perlu menentukan kondisi hidup sesuai perubahan status ekonomi dan kondisi fisik, (4) perlu mencari teman baru untuk menggantikan suami/isteri yang telah meninggal atau pergi jauh atau cacat, (5) perlu mengembangkan kegiatan baru untuk mengisi waktu luang, (6) perlu belajar memperlakukan anak yang sudah besar sebagai orang dewasa, (7) mulai terlibat dalam kegiatan masyarakat, (8) mulai merasakan kebahagiaan dari kegiatan yang sesuai untuk lansia, dan (9) menjadi korban kriminalitas (Ismayadi, 2004). BKKBN (2014), lebih lanjut mengemukakan bahwa lansia mengalami proses menua, yaitu proses alami yang mengubah seseorang dewasa sehat menjadi lemah secara perlahan, dengan berkurangnya fungsi organ tubuh secara normal dan mengakibatkan adanya peningkatan kerentanan. Proses menua ditandai adanya perubahan biologi (fisik), perubahan spiritual, dan perubahan psikososial (psikis dan sosial). Melihat beberapa permasalahan di atas, maka peningkatan jumlah penduduk lansia selain menjadi indikator keberhasilan pembangunan, juga sekaligus menjadi tantangan pembangunan. Oleh sebab itu, permasalahan lansia perlu menjadi perhatian semua pihak, baik pemerintah, swasta, lembaga terkait, masyarakat, maupun keluarga dalam penanggulangan permasalahan tersebut.

Pada seminar hari ulang tahun Persatuan Wredatama Republik Indonesia (PWRI) dan lansia di Daerah Istimewa Yogyakarta tanggal 29 Mei 2012 yang mengangkat tema "Meningkatkan Peran Lansia/Wredatama Republik Indonesia terhadap Kepedulian Tiga 
Generasi melalui Pos Pemberdayaan Keluarga (Posdaya)", dikemukakan tentang pentingnya keberadaan penduduk lansia di Indonesia saat ini. Berbeda dengan penduduk lansia di luar negeri yang dimasukkan ke panti-panti asuhan, penduduk lansia di Indonesia justru harus kembali ke masyarakat dan terlibat dalam pembangunan serta pemberdayaan masyarakat, salah satunya melalui keterlibatan dalam pembentukan dan pengembangan Posdaya baik di perkotaan maupun perdesaan (Ade S., 2012). Oleh karena itu diperlukan adanya perubahan pola pikir yang selama ini menganggap penduduk lansia termasuk kelompok rentan yang menjadi beban keluarga dan masyarakat, dengan menjadikan penduduk lansia sebagai asset negara yang terus diberdayakan sesuai potensinya masingmasing.

Berbagai upaya harus dipersiapkan oleh lansia sendiri maupun keluarganya agar ke depan lansia tetap sehat, aktif, mandiri, dan produktif. Kesiapan lansia untuk tetap peduli pada masa depan dapat dilihat dari 5 (lima) dimensi, yaitu dimensi fisik, psikologis, mental spiritual, sosial kemasyarakatan, dan pengembangan potensi. Keluarga memiliki peranan penting dalam membina kesiapan lansia untuk tetap peduli masa depan, harapannya agar terwujud kualitas keluarga yang sejahtera lahir dan batin. Undang-Undang Republik Indonesia No. 13 Tahun 1998 tentang kesejahteraan lansia, Pasal 1 ayat 1 mengatakan bahwa kesejahteraan adalah suatu tata kehidupan dan penghidupan sosial baik material maupun spiritual yang diliputi oleh rasa keselamatan, kesusilaan dan ketentraman lahir batin yang memungkinkan bagi setiap warga negara untuk mengadakan pemenuhan kebutuhan jasmani, rohani, dan sosial yang sebaik-baiknya bagi diri, keluarga, serta masyarakat dengan menjunjung tinggi hak dan kewajiban asasi manusia sesuai dengan Pancasila. Dengan demikian perlu adanya perhatian dari keluarga terhadap lansia, agar lansia tidak hanya meningkat usia harapan hidupnya, tetapi juga dapat menikmati masa tua dengan bahagia serta dapat meningkatkan kualitas kehidupannya.

Kurangnya dukungan data terbaru kondisi lansia di Daerah Istimewa Yogyakarta berdasarkan dimensi fisik, psikologis, mental spiritual, sosial kemasyarakatan, dan pengembangan potensi merupakan masalah yang harus segera ditindaklanjuti dengan kegiatan penelitian, mengingat data kondisi lansia berdasarkan 5 (lima) dimensi dapat digunakan untuk melihat seberapa besar tingkat kepedulian lansia di Daerah Istimewa Yogyakarta pada masa depannya. Melihat pentingnya kajian lansia dengan 5 (lima) dimensi dalam upaya mengetahui tingkat kepedulian lansia pada masa depannya, maka peneliti tertarik melakukan penelitian tentang "Lanjut Usia (Lansia) Peduli Masa Depan di Daerah Istimewa Yogyakarta".

\section{METODE}

Penelitian ini merupakan penelitian deskriptif. Dalam penelitian ini difokuskan untuk menggambarkan kondisi lansia di Daerah Istimewa Yogyakarta berdasarkan 5 (lima) dimensi, yaitu dimensi fisik, psikologis, mental spiritual, sosial kemasyarakatan, dan pengembangan potensi, yang selanjutnya dapat digunakan untuk menganalisis tingkat kepedulian lansia pada masa depannya. Variabel dalam penelitian ini adalah kondisi lansia dan tingkat peduli masa depan lansia. Populasi dalam penelitian ini adalah seluruh 
penduduk lansia yang ada di Daerah Istimewa Yogyakarta. Dalam penelitian ini sampel ditentukan menggunakan teknik purposive sampling, yaitu dengan cara mengambil sampel wilayah berdasarkan pertimbangan tertentu. Pertimbangan yang digunakan adalah wilayah yang berpartisipasi dalam penilaian lomba kelompok Bina Keluarga Lansia (BKL) Tahun 2014. Untuk masing-masing kabupaten/kota di Daerah Istimewa Yogyakarta diambil 1 (satu) desa yang mewakili, yaitu meliputi:

1. Kelurahan Wirogunan Kecamatan Mergangsan Kota Yogyakarta.

2. Desa Banguntapan Kecamatan Banguntapan Kabupaten Bantul.

3. Desa Sumbersari Kecamatan Moyudan Kabupaten Sleman.

4. Desa Tuksono Kecamatan Sentolo Kabupaten Kulonprogo.

5. Desa Planjan Kecamatan Saptosari Kabupaten Gunungkidul.

Adapun jumlah lansia yang menjadi responden penelitian ditentukan secara kuota sampling, masing-masing kabupaten/kota diambil 50 orang responden, terdiri dari 25 orang lansia peserta $B K L$ dan 25 orang lansia non peserta $B K L$, sehingga total responden sebanyak 250 orang lansia. Jenis data yang dikumpulkan dalam penelitian ini meliputi data primer dan data sekunder. Data primer diperoleh dengan teknik pengumpulan data melalui observasi dan wawancara, sedangkan data sekunder diperoleh melalui dokumentasi.

Data yang telah dikumpulkan selanjutnya dilakukan pengelolaan data. Langkahlangkah pengelolaan data dalam penelitian ini meliputi kegiatan editing, koding, dan tabulasi. Setelah ditabulasi selanjutnya data dianalisis secara deskriptif kuantitatif. Penelitian ini menggunakan analisis kuantitatif yaitu analisis non statistik dengan tabel frekuensi. Analisis deskriptif kuantitatif adalah proses penyederhanaan data secara deskriptif, yaitu dengan tabel frekuensi. Metode analisis ini dapat digunakan untuk mendeskripsikan kondisi lansia di Daerah Istimewa Yogyakarta dilihat dari 5 (lima) dimensi, yang selanjutnya dapat dinilai tingkat peduli masa depan lansia. Tingkat peduli masa depan lansia dapat diperoleh dari asumsi nilai skoring masing-masing dimensi yang hasilnya dapat dibagi menjadi 3 (tiga) tingkat, yaitu tingkat rendah, sedang, atau tinggi.

\section{HASIL DAN PEMBAHASAN}

\section{Lansia Peduli Masa Depan Berdasarkan Lima Dimensi Dimensi Fisik}

Dimensi fisik meliputi perubahan fisik, perubahan mental, perubahan sosial, memerlukan alat bantu, perubahan kondisi kesehatan reproduksi, mengalami gangguan penyakit, terus memelihara kondisi fisik, dan melakukan pemeriksaan kesehatan. Kondisi lansia di daerah penelitian secara keseluruhan sebagian besar telah mengalami perubahan fisik, untuk lansia peserta BKL sebesar 90\% dan lansia non peserta BKL sebesar $94 \%$. Perubahan fisik lansia seperti kondisi fisik semakin menurun, pendengaran atau penglihatan berkurang, kulit keriput, dan rambut memutih. Jika dilihat dari persentasenya lansia peserta BKL mengalami perubahan fisik dengan persentase lebih kecil dibandingkan lansia non peserta BKL, hal ini menunjukkan bahwa adanya BKL di daerah penelitian dimungkinkan membantu mengurangi perubahan fisik pada lansia. 
Responden di daerah penelitian secara keseluruhan mengalami perubahan mental lebih besar pada lansia non peserta BKL (66\%) jika dibandingkan dengan lansia peserta BKL (57\%). Kondisi yang sama juga ditemui di Kabupaten Sleman, Kulonprogo, dan Gunungkidul. Hal ini menunjukkan bahwa adanya BKL di daerah penelitian dimungkinkan membantu mengurangi perubahan mental pada lansia. Kondisi sebaliknya terjadi di Kota Yogyakarta dan Kabupaten Bantul, dimana lansia peserta BKL persentasenya justru lebih besar mengalami perubahan mental jika dibandingkan dengan lansia non peserta BKL. Hal ini tentunya menuntut peningkatan peran BKL di kedua daerah tersebut untuk membantu lansia mengurangi perubahan mental, sehingga lansia tetap peduli masa depannya. Perubahan mental yang dialami lansia, antara lain suka menyendiri, sulit tidur, sedih ditinggal pasangan, merasa tidak diperhatikan, dan mudah tersinggung.

Dari aspek perubahan sosial diketahui bahwa lansia peserta BKL di daerah penelitian secara keseluruhan lebih kecil persentasenya mengalami perubahan sosial (11\%) jika dibandingkan dengan lansia non peserta BKL (34\%). Kondisi yang sama juga ditemui di semua kabupaten/kota. Hal ini menunjukkan bahwa adanya BKL di daerah penelitian dimungkinkan dapat membantu lansia dalam mengurangi perubahan sosial, sehingga lansia tetap peduli masa depannya. Perubahan sosial pada lansia, antara lain: jarang mengikuti kegiatan arisan RT/RW, jarang mengikuti pengajian, dan jarang kerja bakti karena lebih suka menyendiri daripada berkumpul dengan teman sebaya.

Lansia peserta BKL di daerah penelitian secara keseluruhan persentasenya lebih besar memerlukan alat bantu (59\%) jika dibandingkan dengan lansia non peserta BKL (43\%). Kondisi yang sama juga ditemui di Kota Yogyakarta, Kabupaten Bantul, Sleman, dan Gunungkidul. Hal ini tentunya memerlukan peningkatan peran BKL di daerah penelitian untuk membantu lansia tetap peduli masa depan dengan mengurangi ketergantungan terhadap alat bantu. Kondisi sebaliknya terjadi di Kabupaten Kulonprogo, dimana lansia peserta BKL persentasenya lebih sedikit memerlukan alat bantu (64\%) jika dibandingkan lansia non peserta BKL (68\%). Alat bantu yang kebanyakan telah digunakan lansia adalah kacamata.

Lansia non peserta BKL di daerah penelitian secara keseluruhan memiliki persentase lebih besar mengalami perubahan kondisi kesehatan reproduksi (70\%) jika dibandingkan dengan lansia peserta BKL (65\%). Kondisi yang sama juga ditemui di 3 (tiga) kabupaten, yaitu Kabupaten Sleman, Kulonprogo, dan Gunungkidul. Hal ini menunjukkan bahwa adanya BKL di ketiga daerah tersebut dimungkinkan telah membantu lansia untuk mengurangi perubahan kondisi kesehatan reproduksi. Beda halnya dengan Kota Yogyakarta dan Kabupaten Bantul yang memiliki persentase perubahan kondisi kesehatan reproduksi lebih besar pada lansia peserta BKL jika dibandingkan lansia non peserta BKL, sehingga diperlukan adanya peningkatan peran BKL dalam mengurangi perubahan kondisi kesehatan reproduksi lansia, sehingga lansia tetap peduli masa depannya.

Lansia non peserta BKL di daerah penelitian secara keseluruhan lebih besar persentasenya mengalami gangguan penyakit (51\%) jika dibandingkan lansia peserta BKL (46\%). Kondisi yang sama juga ditemui di Kabupaten Sleman, Kulonprogo, dan Gunungkidul. Hal ini menunjukkan adanya BKL di ketiga daerah penelitian telah membantu 
lansia dalam mengurangi gangguan penyakit. Kondisi ini beda halnya dengan lansia di Kota Yogyakarta dan Kabupaten Bantul, dimana lansia peserta BKL memiliki persentase lebih besar mengalami gangguan penyakit jika dibandingkan lansia non peserta $B K L$, sehingga memerlukan peningkatan peran BKL di kedua daerah tersebut untuk mengurangi gangguan penyakit lansia dengan berbagai program. Gangguan penyakit yang dialami lansia, seperti tekanan darah tinggi, jantung, asam urat, ginjal, pusing, sakit perut, dan mudah capek.

Berdasarkan aspek terus memelihara kondisi fisik, diketahui bahwa lansia peserta BKL dan non peserta BKL di daerah penelitian secara keseluruhan persentasenya sama besar dalam memelihara kondisi fisiknya, yaitu sebesar $96 \%$. Kondisi sama dijumpai di Kabupaten Kulonprogo dan Gunungkidul dimana semua lansia melakukan pemeliharaan kondisi fisik (100\%). Untuk Kabupaten Sleman, lansia peserta BKL persentasenya lebih besar dalam memelihara kondisi fisik jika dibandingkan lansia non perserta BKL, sedangkan untuk Kota Yogyakarta dan Kabupaten Bantul lansia non peserta BKL lebih besar persentasenya dalam memelihara kondisi fisik jika dibandingkan lansia peserta BKL. Kondisi ini menuntut peningkatan peran BKL di kedua daerah tersebut untuk memotivasi lansia terus memelihara kondisi fisik sebagai wujud peduli masa depan. Upaya pemeliharaan kondisi fisik dilakukan lansia dengan istirahat cukup, makan makanan sehat, tidak merokok dan minum-minuman keras, rutin periksa, dan jalan sehat.

Lansia peserta BKL di daerah penelitian secara keseluruhan memiliki persentase lebih besar untuk secara rutin melakukan pemeriksaan kesehatan (90\%) jika dibandingkan lansia non peserta BKL (83\%). Kondisi sama juga ditemui di hampir semua kabupaten/kota, kecuali Kabupaten Bantul, sehingga memerlukan peningkatan peran BKL di Kabupaten Bantul untuk terus memotivasi lansia agar secara rutin melakukan pemeriksaan kesehatan sebagai wujud peduli masa depannya. Pemeriksaan kesehatan secara rutin oleh lansia dapat dilakukan di posyandu lansia dan puskesmas. Peran keluarga dalam menjaga kesehatan lansia selain mengantarkan berobat, juga dengan mengontrol makanan lansia.

Tingkat peduli masa depan lansia di daerah penelitian secara keseluruhan pada dimensi fisik berada pada tingkat kategori sedang, baik untuk lansia peserta BKL dan non peserta BKL. Hal ini juga dijumpai pada semua kabupaten/kota, kecuali pada Kabupaten Gunungkidul tingkat peduli masa depan lansia peserta BKL pada dimensi fisik termasuk kategori tinggi (Tabel 1)

Tabel 1. Tingkat peduli masa depan lansia dimensi fisik

\begin{tabular}{|c|l|l|l|l|l|}
\hline \multirow{2}{*}{ No. } & Tingkat peduli masa & \multicolumn{2}{|l|}{ Lansia peserta BKL } & Lansia non peserta BKL \\
\cline { 3 - 6 } & depan dimensi fisik & Skor & Kategori & Skor & Kategori \\
\hline 1. & Kota Yogyakarta & 3,72 & Sedang & 4,24 & Sedang \\
\hline 2. & Kabupaten Bantul & 3,44 & Sedang & 4,48 & Sedang \\
\hline 3. & Kabupaten Sleman & 5,16 & Sedang & 4,52 & Sedang \\
\hline 4. & Kabupaten Kulonprogo & 4,88 & Sedang & 3,72 & Sedang \\
\hline 5. & Kabupaten Gunungkidul & 5,72 & Tinggi & 4,04 & Sedang \\
\hline & Jumlah (DIY) & 4,58 & Sedang & 4,20 & Sedang \\
\hline
\end{tabular}

Sumber: data primer, 2014 


\section{Dimensi Psikologis}

Dimensi psikologis meliputi gangguan persepsi, penurunan konsentrasi, mengalami gangguan bahasa dan komunikasi, mengalami penurunan daya ingat, terus melakukan aktifitas untuk mengaktifkan kerja otak, mengalami perubahan aspek emosi dan perasaan, mengalami perubahan sikap dan perilaku, mengalami permasalahan psikologis, melakukan upaya untuk menghadapi permasalahan emosional, dan keluarga telah melakukan upaya untuk mengatasi permasalahan emosional responden. Sebagian besar responden di daerah penelitian secara keseluruhan mengalami gangguan persepsi, sebesar $61 \%$ untuk lansia peserta BKL dan $70 \%$ untuk lansia non peserta BKL. Jumlah lansia non peserta BKL memiliki persentase lebih besar mengalami gangguan persepsi juga dijumpai di Kabupaten Kulonprogo dan Gunungkidul. Hal ini menunjukkan bahwa adanya BKL di daerah penelitian dapat mengurangi gangguan persepsi pada lansia, sehingga lansia tetap peduli masa depannya. Kondisi tersebut berbeda dengan 3 (tiga) kabupaten lainnya, yaitu Kota Yogyakarta, Kabupaten Bantul dan Sleman yang memiliki persentase sama gangguan persepsi antara lansia peserta BKL dan lansia non peserta BKL. Gangguan persepsi yang dijumpai pada lansia berupa mudah sedih, mudah marah, mudah tersinggung dan suka mengeluh.

Responden yang mengalami penurunan konsentrasi untuk lansia peserta BKL dan non peserta BKL di daerah penelitian secara keseluruhan persentasenya sama, yaitu sebesar $66 \%$. Kondisi ini juga dijumpai di Kabupaten Kulonprogo. Lansia peserta BKL di Kota Yogyakarta dan Kabupaten Bantul mengalami penurunan konsentrasi lebih besar dibandingkan lansia non peserta BKL, sedangkan di Kabupaten Sleman dan Gunungkidul lansia non peserta BKL mengalami penurunan konsentrasi lebih besar dibandingkan lansia peserta BKL. Hal ini menuntut peningkatan peran BKL di Kota Yogyakarta dan Kabupaten Bantul untuk membantu mengurangi penurunan konsentrasi lansia di wilayahnya sehingga lansia tetap peduli masa depan. Penurunan konsentrasi lansia diantaranya lansia kesulitan memusatkan perhatian dan perhatian lansia terpecah.

Responden di daerah penelitian secara keseluruhan mengalami gangguan bahasa dan komunikasi untuk lansia peserta BKL sebesar $46 \%$, atau lebih besar dibandingkan lansia non peserta BKL (40\%). Kondisi lansia peserta BKL di hampir semua kabupaten/kota lebih besar persentasenya mengalami gangguan bahasa dan komunikasi, kecuali di Kabupaten Kulonprogo. Kondisi ini memerlukan peningkatan peran BKL dalam membantu lansia di wilayahnya untuk mengurangi gangguan bahasa dan komunikasi agar tetap peduli masa depan. Gangguan bahasa dan komunikasi, antara lain lupa kosa kata serta berbicara pelan dan lama.

Penurunan daya ingat pada responden di daerah penelitian secara keseluruhan lebih besar persentasenya pada lansia non peserta BKL (69\%) jika dibandingkan lansia peserta BKL (62\%). Kondisi yang sama juga ditemui di Kabupaten Kulonprogo dan Gunungkidul, sedangkan di Kabupaten Bantul dan Sleman penurunan daya ingat persentasenya lebih besar untuk lansia peserta BKL, dan untuk Kota Yogyakarta persentasenya sama. Hal ini memerlukan peningkatan peran BKL khususnya di Kabupaten Bantul dan Sleman untuk membantu lansia di wilayahnya dalam mengurangi gangguan penurunan daya ingat 
sehingga lansia tetap peduli masa depan. Penurunan daya ingat yang dialami lansia, antara lain lupa peristiwa, lupa nama orang, dan lupa meletakkan sesuatu

Lansia peserta BKL dan non peserta BKL di daerah penelitian secara keseluruhan memiliki persentase sama dalam melakukan aktivitas untuk mengaktifkan kerja otak, yaitu sebesar 94\%. Kondisi sama juga ditemui di Kota Yogyakarta dan Kabupaten Bantul. Untuk Kabupaten Sleman dan Kulonprogo persentase lansia peserta BKL melakukan aktivitas untuk mengaktifkan kerja otak lebih besar dibandingkan yang non peserta BKL, kondisi sebaliknya untuk Kabupaten Gunungkidul dimana lansia peserta BKL lebih sedikit melakukan aktivitas untuk mengaktifkan kerja otak daripada lansia non peserta BKL. Hal ini menuntut peningkatan peran BKL di Kabupaten Gunungkidul khususnya untuk mendorong lansia di wilayahnya untuk terus melakukan aktivitas untuk mengaktifkan kerja otak sebagai wujud peduli masa depan.

Lansia non peserta BKL di daerah penelitian secara keseluruhan persentasenya lebih besar mengalami perubahan emosi (52\%) jika dibandingkan dengan lansia peserta BKL (37\%). Kondisi sama juga ditemui di hampir semua kabupaten/kota, kecuali Kota Yogyakarta. Hal ini menunjukkan bahwa keberadaan BKL di daerah penelitian cukup mendukung dalam membantu mengurangi perubahan emosi yang dialami lansia. Perubahan emosi yang dialami lansia adalah perubahan aspek psikologis seperti mudah marah dan mudah curiga serta perubahan aspek biologis seperti merasa tidak diperhatikan dan sering buang air kecil.

Lansia di DIY yang non peserta BKL lebih banyak mengalami perubahan sikap dan perilaku (63\%) jika dibandingkan lansia peserta BKL (46\%). Kondisi sama juga ditemui di Kabupaten Kulonprogo dan Gunungkidul. Perubahan sikap dan perilaku lansia, seperti mundurnya psikomotorik, merasa kurang menarik, perubahan jalinan hubungan sosial, dan bermimpi masa lalu.

Lansia non peserta BKL di daerah penelitian secara keseluruhan memiliki persentase lebih besar mengalami permasalahan psikologis (35\%) jika dibandingkan lansia peserta BKL (30\%). Kondisi yang sama juga ditemui di Kabupaten Bantul, Sleman, dan Gunungkidul. Hal ini menunjukkan peran BKL dalam membantu mengurangi permasalahan psikologis lansia di wilayahnya. Kondisi ini beda halnya dengan Kota Yogyakarta dan Kabupaten Kulonprogo, dimana lansia peserta BKL memiliki persentase lebih besar mengalami permasalahan psikologis dibandingkan lansia non peserta BKL. Kondisi ini menuntut peranan BKL di kedua wilayah tersebut untuk membantu mengurangi permasalahan psikologis lansia agar lansia tetap peduli masa depannya. Permasalahan psikologis lansia, diantaranya merasa takut, kehilangan rasa percaya diri, merasa kesepian, mudah marah, dan memperoleh kekerasan

Lansia di daerah penelitian secara keseluruhan yang non peserta BKL persentasenya lebih besar melakukan upaya menghadapi permasalahan emosional (93\%) jika dibandingkan lansia peserta BKL (88\%). Kondisi yang sama juga terjadi di Kabupaten Bantul, Sleman, dan Kulonprogo. Hal ini menunjukkan bahwa lansia non peserta BKL lebih peduli pada masa depannya dengan melakukan berbagai upaya menghadapi permasalahan emosional, sehingga peranan BKL di wilayah ini untuk membantu lansia melakukan berbagai upaya menghadapi permasalahan emosional perlu lebih ditingkatkan. 
Keluarga lansia peserta BKL di daerah penelitian secara keseluruhan persentasenya lebih besar dalam melakukan upaya untuk mengatasi permasalahan emosional responden (87\%) jika dibandingkan keluarga lansia non peserta BKL (80\%). Kondisi yang sama juga ditemui di 3 (tiga) kabupaten, meliputi Kota Yogyakarta, Kabupaten Bantul dan Gunungkidul. Hal ini menunjukkan bahwa BKL mampu meningkatkan peran keluarga dalam mengatasi permasalahan emosional responden, yaitu dengan membimbing lansia, mengajak komunikasi lansia, dan memenuhi kebutuhan lansia. Kondisi di atas beda halnya dengan Kabupaten Sleman, dimana antara lansia peserta BKL dan lansia non peserta BKL, peran keluarga dalam melakukan upaya mengatasi permasalahan emosional lansia memiliki persentase sama, sedangkan untuk Kabupaten Kulonprogo lansia non peserta BKL keluarganya justru lebih berperan dalam melakukan berbagai upaya mengatasi permasalahan emosional responden jika dibandingkan lansia peserta BKL. Kondisi ini memerlukan peningkatan peran BKL di Kabupaten Kulonprogo dalam melakukan berbagai upaya mengatasi permasalahan emosional lansia.

Tingkat peduli masa depan lansia di daerah penelitian secara keseluruhan pada dimensi psikologis berada pada tingkat kategori sedang, baik untuk lansia peserta BKL maupun lansia non peserta BKL. Hal ini juga dijumpai pada semua kabupaten/kota, kecuali pada Kabupaten Gunungkidul tingkat peduli masa depan lansia peserta BKL pada dimensi psikologis termasuk kategori tinggi (Tabel 2).

Tabel 2. Tingkat peduli masa depan lansia dimensi psikologis

\begin{tabular}{|c|l|c|c|c|c|}
\hline \multirow{2}{*}{ No. } & \multirow{2}{*}{$\begin{array}{c}\text { Tingkat peduli masa depan } \\
\text { dimensi psikologis }\end{array}$} & \multicolumn{2}{|c|}{ Lansia peserta BKL } & \multicolumn{2}{c|}{ Lansia non peserta BKL } \\
\cline { 3 - 6 } & Skor & Kategori & Skor & Kategori \\
\hline 1. & Kota Yogyakarta & 4,72 & Sedang & 5,72 & Sedang \\
\hline 2. & Kabupaten Bantul & 6,04 & Sedang & 6,00 & Sedang \\
\hline 3. & Kabupaten Sleman & 6,56 & Sedang & 6,40 & Sedang \\
\hline 4. & Kabupaten Kulonprogo & 6,24 & Sedang & 5,24 & Sedang \\
\hline 5. & Kabupaten Gunungkidul & 7,52 & Tinggi & 5,24 & Sedang \\
\hline & Jumlah (DIY) & 6,22 & Sedang & 5,72 & Sedang \\
\hline
\end{tabular}

Sumber: data primer, 2014

\section{Dimensi Mental Spiritual}

Dimensi mental spiritual meliputi peran agama bagi kehidupan, beriman kepada tuhan, peran kader BKL dalam memperkuat keimanan responden, peran keluarga dalam memperkuat keimanan, dan peran masyarakat dalam menentukan keimanan. Di daerah penelitian secara keseluruhan semua lansia peserta BKL menyakini peran agama bagi kehidupannya (100\%), sedangkan untuk lansia non peserta BKL sebesar 99\% menyakini peran agama bagi kehidupannya. Kondisi ini dijumpai di semua kabupaten/kota, kecuali Kabupaten Sleman untuk lansia non peserta BKL (96\%). Hal ini menunjukkan peran BKL dalam membantu lansia menyakini peran agama bagi kehidupannya. Agama berperan bagi kehidupan lansia dalam mengurangi rasa takut dan cemas, lebih mendekatkan diri kepada Tuhan, serta kebahagiaan dunia akhirat. 
Semua lansia di daerah penelitian secara keseluruhan yang peserta BKL beriman kepada Tuhan (100\%), sedangkan untuk lansia non peserta BKL sebesar 99\% beriman kepada Tuhan. Kondisi ini dijumpai di semua kabupaten/kota, kecuali Kota Yogyakarta untuk lansia non peserta BKL (96\%). Hal ini menunjukkan bahwa BKL berperan dalam membantu lansia meningkatkan keimanannya kepada Tuhan.

Sebagian besar responden di daerah penelitian secara keseluruhan menyatakan peran kader BKL dalam memperkuat keimanan responden, sebesar $99 \%$ untuk lansia peserta BKL dan sebesar 70\% untuk lansia non peserta BKL. Kondisi ini juga dijumpai di setiap kabupaten/kota, dimana lansia yang peserta BKL lebih menyakini peran BKL dalam memperkuat keimanan karena mereka merasakan peran BKL dalam membimbing beribadah dan pasrah terhadap kehidupan.

Sebagian besar lansia di daerah penelitian secara keseluruhan menyakini peran keluarga dalam memperkuat keimanan, masing-masing sebesar $98 \%$ untuk lansia peserta BKL dan lansia non peserta BKL, bahkan untuk Kota Yogyakarta dan Kabupaten Bantul (lansia peserta BKL dan lansia non peserta BKL), Kabupaten Kulonprogo (lansia non peserta BKL), dan Kabupaten Gunungkidul (lansia peserta BKL) diketahui semua lansia (100\%) menyakini peran keluarga dalam memperkuat keimanan. Peran keluarga dalam memperkuat keimanan, yaitu mengingatkan waktu sholat, mengajak lansia melaksanakan ibadah bersama, membimbing kepasrahan kepada Tuhan, dan mensyukuri nikmat Tuhan.

Semua responden di daerah penelitian secara keseluruhan untuk lansia peserta BKL (100\%) menyakini peran masyarakat dalam memperkuat keimanan, sedangkan untuk lansia non peserta BKL sebesar 98\%. Hampir semua kabupaten/kota di daerah penelitian menyakini peran masyarakat dalam memperkuat keimanan, kecuali di Kabupaten Sleman untuk lansia non peserta BKL (92\%). Peran masyarakat dalam memperkuat keimanan lansia, antara lain memberikan ruang dan kesempatan sama untuk beribadah, membimbing ibadah secara rutin, memberikan fasilitas keagamaan, dan menyelenggarakan perayaan keagamaan.

Tingkat peduli masa depan lansia di daerah penelitian secara keseluruhan pada dimensi mental spiritual berada pada tingkat kategori tinggi, baik untuk lansia peserta BKL dan non peserta BKL. Hal ini juga dijumpai pada semua kabupaten/kota di daerah penelitian (Tabel 3).

Tabel 3 Tingkat peduli masa depan lansia dimensi mental spiritual

\begin{tabular}{|c|l|c|c|c|c|}
\hline \multirow{2}{*}{ No. } & $\begin{array}{c}\text { Tingkat peduli masa } \\
\text { depan dimensi mental } \\
\text { spiritual }\end{array}$ & \multicolumn{2}{|c|}{ Lansia peserta BKL } & \multicolumn{2}{c|}{ Lansia non peserta BKL } \\
\cline { 3 - 6 } & Skor & Kategori & Skor & Kategori \\
\hline 1. & Kota Yogyakarta & 5,00 & Tinggi & 4,68 & Tinggi \\
\hline 2. & Kabupaten Bantul & 5,00 & Tinggi & 4,72 & Tinggi \\
\hline 3. & Kabupaten Sleman & 4,92 & Tinggi & 4,64 & Tinggi \\
\hline 4. & Kabupaten Kulonprogo & 4,96 & Tinggi & 4,44 & Tinggi \\
\hline 5. & Kabupaten Gunungkidul & 5,00 & Tinggi & 4,72 & Tinggi \\
\hline & Jumlah (DIY) & 4,98 & Tinggi & 4,64 & Tinggi \\
\hline
\end{tabular}




\section{Dimensi Sosial Kemasyarakatan}

Dimensi sosial kemasyarakatan meliputi melakukan upaya untuk membangun kepedulian dengan sesama, merasa penting adanya perlindungan bagi lansia, turut berpartisipasi dalam kegiatan sosial kemasyarakatan, melakukan interaksi sosial dengan orang lain (keluarga, masyarakat),

Lansia peserta BKL di daerah penelitian secara keseluruhan lebih membangun upaya kepedulian terhadap sesama, yaitu dengan persentase sebesar 99\% jika dibandingkan lansia non peserta BKL (98\%). Kondisi sama juga dijumpai di Kota Yogyakarta dan Kabupaten Bantul, sedangkan di Kabupaten Sleman dan Gunungkidul semua lansia telah melakukan kepedulian terhadap sesama (100\%) dan untuk Kabupaten Kulonprogo lansia non peserta BKL justru lebih besar persentasenya dalam melakukan kepedulian terhadap sesama jika dibandingkan dengan lansia peserta BKL. Hal ini perlu menjadi perhatian BKL di Kabupaten Kulonprogo khususnya dalam memotivasi lansia untuk terus melakukan upaya membangun kepedulian dengan sesama sebagai wujud peduli masa depannya. Upaya yang dilakukan lansia untuk membangun kepedulian dengan sesama, antara lain: bersedekah, kerja bakti, melayat, mengunjungi teman atau kerabat yang sakit, dan melakukan silaturahim.

Lansia peserta BKL dan non peserta BKL di daerah penelitian secara keseluruhan memiliki persentase sama besar (98\%) terhadap pentingnya perlindungan sosial. Perlindungan sosial lansia diantaranya diperhatikan kebutuhannya, dibimbing, dan dihormati. Pentingnya perlindungan lansia mengingat adanya perlindungan bagi lansia menjadikan lansia merasa senang, tentram, dan berguna sehingga akan lebih peduli masa depannya.

Lansia peserta BKL dan non peserta BKL di daerah penelitian secara keseluruhan memiliki persentase hampir sama besar, yaitu 94\% (lansia peserta BKL) dan 93\% (lansia non peserta BKL) dalam berpartisipasi di kegiatan sosial kemasyarakatan. Lansia peserta BKL di Kabupaten Bantul, Sleman, dan Gunungkidul lebih banyak berpartisipasi dalam kegiatan sosial kemasyarakatan, hal ini beda halnya dengan lansia peserta BKL di Kota Yogyakarta dan Kabupaten Kulonprogo yang lebih sedikit berpartisipasi dalam kegiatan sosial kemasyarakatan. Kondisi ini tentunya membutuhkan peningkatan peran BKL di Kota Yogyakarta dan Kabupaten Kulonprogo untuk terus mendorong lansia di wilayahnya terus berpartisipasi dalam kegiatan sosial kemasyarakatan sebagai bentuk kepedulian terhadap masa depannya. Kegiatan sosial kemasyarakatan yang diikuti lansia di daerah penelitian, seperti pengajian, arisan, olah raga, posyandu lansia, kerja bakti, kerajinan, dan seni budaya.

Lansia non peserta BKL di daerah penelitian secara keseluruhan lebih banyak melakukan interaksi sosial dengan orang lain (94\%) jika dibandingkan lansia peserta BKL (86\%). Kondisi yang sama juga ditemui di Kota Yogyakarta, Kabupaten Kulonprogo dan Gunungkidul. Kondisi ini menunjukkan perlunya peningkatan peran BKL di 3 (tiga) kabupaten tersebut untuk memotivasi lansia di wilayahnya terus melakukan interaksi dengan orang lain sebagai wujud peduli masa depannya. Cara interaksi sosial lansia dengan orang lain, antara lain: mengobrol dengan teman, menanggapi pertanyaan teman dengan baik, melakukan interaksi dalam suasana santai. 
Tingkat peduli masa depan lansia di daerah penelitian secara keseluruhan pada dimensi sosial kemasyarakatan berada pada tingkat kategori tinggi, baik lansia peserta BKL dan non peserta BKL. Hal ini juga dijumpai pada semua kabupaten/kota (Tabel 4)

Tabel 4. Tingkat peduli masa depan lansia dimensi sosial kemasyarakatan

\begin{tabular}{|c|l|c|c|c|c|}
\hline \multirow{2}{*}{ No. } & \multirow{2}{*}{$\begin{array}{c}\text { Tingkat peduli masa depan } \\
\text { dimensi sosial kemasyarakatan }\end{array}$} & \multicolumn{2}{|c|}{ Lansia peserta BKL } & \multicolumn{2}{c|}{ Lansia non peserta BKL } \\
\cline { 3 - 6 } & Skor & Kategori & Skor & Kategori \\
\hline 1. & Kota Yogyakarta & 3,72 & Tinggi & 3,80 & Tinggi \\
\hline 2. & Kabupaten Bantul & 4,00 & Tinggi & 3,84 & Tinggi \\
\hline 3. & Kabupaten Sleman & 4,00 & Tinggi & 3,88 & Tinggi \\
\hline 4. & Kabupaten Kulonprogo & 3,68 & Tinggi & 3,92 & Tinggi \\
\hline 5. & Kabupaten Gunungkidul & 3,52 & Tinggi & 3,72 & Tinggi \\
\hline & Jumlah (DIY) & 3,78 & Tinggi & 3,83 & Tinggi \\
\hline
\end{tabular}

\section{Dimensi Pengembangan Potensi}

Dimensi pengembangan potensi meliputi melakukan berbagai peluang pengembangan profesi, melakukan berbagai peluang dalam pengembangan usaha ekonomi produktif, melakukan pertimbangan dalam penetapan jenis usaha yang dilakukan, berpartisipasi di kegiatan lingkungan fisik, melakukan berbagai upaya untuk menjaga lingkungan menjadi aman, bersih, dan nyaman, berpartisipasi di kegiatan lingkungan non fisik, terus melakukan berbagai upaya untuk memperoleh ketenangan batin, dan terus melakukan berbagai upaya untuk saling komunikasi dan tukar informasi.

Lansia peserta BKL di daerah penelitian secara keseluruhan persentasenya lebih banyak melakukan pengembangan profesi (64\%) jika dibandingkan lansia non peserta BKL (59\%). Hal ini juga dijumpai di Kabupaten Sleman, Kulonprogo, dan Gunungkidul. Kondisi ini menunjukkan peran BKL di daerah penelitian dalam memotivasi lansia terus mengembangkan profesinya sebagai wujud lansia peduli masa depannya. Pengembangan profesi lansia dilakukan melalui usaha jualan, membuat kerajinan, berkebun, beternak, melakukan penyuluhan, dan mengasuh cucu. Peran keluarga dalam pengembangan profesi lansia adalah mendampingi sesuai kemampuan.

Lansia peserta BKL di daerah penelitian secara keseluruhan lebih banyak melakukan pengembangan usaha ekonomi produktif (52\%) jika dibandingkan lansia non peserta BKL (50\%). Kondisi ini juga dijumpai di Kabupaten Sleman dan Kulonprogo. Hal ini menunjukkan peran BKL di kedua wilayah tersebut dalam melakukan pendampingan bagi lansia untuk melakukan pengembangan usaha ekonomi produktif. Pengembangan usaha ekonomi produktif yang dilakukan lansia, antara lain: beternak, berdagang, membuka warung, membuka kos, kerajinan dan pijat. Untuk Kota Yogyakarta dan Kabupaten Gunungkidul, pengembangan usaha ekonomi produktif yang dilakukan lansia peserta BKL dan non peserta BKL persentasenya sama, sedangkan untuk Kabupaten Bantul lansia non peserta BKL justru lebih banyak melakukan pengembangan usaha ekonomi produktif jika dibandingkan lansia peserta BKL. Kondisi ini memerlukan peningkatan peran BKL di Kabupaten Bantul khususnya dalam mendampingi lansia di wilayahnya untuk terus 
melakukan pengembangan usaha ekonomi produktif sebagai wujud peduli masa depannya.

Lansia peserta BKL di daerah penelitian secara keseluruhan lebih banyak melakukan pertimbangan penetapan jenis usaha (60\%) jika dibandingkan lansia non peserta BKL (32\%). Kondisi ini juga ditemui di hampir semua kabupaten/kota, kecuali Kota Yogyakarta. Pertimbangan yang diberikan lansia, antara lain tenaga atau kemampuan, keterampilan yang dimiliki, waktu, dana, dan ketersediaan sarana prasarana.

Lansia non peserta BKL di daerah penelitian secara keseluruhan lebih banyak berpartisipasi dalam kegiatan lingkungan fisik (88\%) jika dibandingkan lansia peserta BKL (85\%). Kondisi ini juga ditemui di Kota Yogyakarta, Kabupaten Kulonprogo dan Gunungkidul. Kondisi ini menunjukkan bahwa BKL di 3 (tiga) kabupaten perlu meningkatkan perannya dalam memotivasi dan mendampingi lansia di wilayahnya untuk terus berpartisipasi dalam kegiatan lingkungan fisik.

Di Kabupaten Bantul semua lansia (100\%), baik peserta BKL maupun non peserta BKL berpartisipasi di kegiatan lingkungan fisik dan di Kabupaten Sleman lansia peserta BKL lebih banyak berpartisipasi di kegiatan lingkungan fisik daripada lansia non peserta BKL. Kondisi ini menunjukkan peran BKL dalam mendorong lansia di wilayahnya terus berpartisipasi di kegiatan lingkungan fisik sebagai wujud peduli masa depannya. Partisipasi lansia di kegiatan lingkungan fisik di daerah penelitian dilakukan dengan pertimbangan kemampuan tenaga, waktu, dana, dan mudahnya kegiatan yang dilakukan.

Semua lansia peserta BKL di daerah penelitian (100\%) menjaga lingkungan di sekitarnya tetap aman, bersih, dan nyaman, sedangkan untuk lansia yang non peserta BKL sebesar 98\%. Kondisi yang menunjukkan semua lansia peserta BKL menjaga lingkungan aman, bersih dan nyaman juga dijumpai di seluruh kabupaten/kota. Bentuk partisipasi lansia menjadikan lingkungan aman, bersih, dan nyaman adalah menyediakan tempat sampah dan membersihkan rumah semampunya.

Bahwa lansia peserta BKL di daerah penelitian secara keseluruhan lebih banyak berpartisipasi di kegiatan lingkungan non fisik yaitu sebesar 88\% jika dibandingkan lansia non peserta BKL (78\%). Hal ini juga ditemui di hampir semua kabupaten/kota, kecuali Kabupaten Bantul. Kondisi ini menunjukkan bahwa keberadaan BKL di daerah penelitian membantu meningkatkan partisipasi lansia di kegiatan lingkungan non fisik, seperti kegiatan mental spiritual dan sosial budaya. Pertimbangan yang dilakukan lansia untuk berpartisipasi di kegiatan lingkungan non fisik, antara lain memperoleh ketenangan batin, saling komunikasi dan tukar informasi.

Lansia peserta BKL di daerah penelitian secara keseluruhan lebih banyak melakukan upaya memperoleh ketenangan batin (99\%) jika dibandingkan lansia non peserta BKL (97\%). Kondisi ini juga dijumpai di Kota Yogyakarta, Kabupaten Sleman dan Kulonprogo, bahkan di Kabupaten Bantul dan Gunungkidul baik lansia peserta BKL dan non peserta BKL semuanya telah melakukan upaya untuk memeperoleh ketenangan batin. Upaya yang dilakukan lansia untuk memperoleh ketenangan batin, antara lain rileks, ikut kegiatan spiritual, rajin beribadah, ikut olah raga, dan ikut organisasi/perkumpulan. 
Lansia peserta BKL di daerah penelitian secara keseluruhan lebih banyak melakukan upaya untuk saling komunikasi dan tukar informasi (98\%) jika dibandingkan lansia non peserta BKL (92\%). Kondisi ini juga ditemui di Kota Yogyakarta, Kabupaten Sleman dan Kulonprogo, bahkan di Kabupaten Bantul dan Gunungkidul baik lansia peserta BKL dan non peserta BKL semuanya telah melakukan upaya untuk saling komunikasi dan tukar informasi. Upaya yang dilakukan lansia untuk saling komunikasi dan tukar informasi adalah ikut kegiatan sosial kemasyarakatan serta mengikuti kegiatan lansia seperti senam lansia dan posyandu lansia. tingkat peduli masa depan lansia di daerah penelitian secara keseluruhan pada dimensi pengembangan potensi berada pada tingkat kategori tinggi, baik untuk lansia peserta BKL maupun lansia non peserta BKL. Hal ini juga dijumpai pada semua kabupaten/kota (Tabel 5)

Tabel 5. Tingkat peduli masa depan lansia dimensi pengembangan potensi

\begin{tabular}{|c|l|c|c|c|c|}
\hline \multirow{2}{*}{ No. } & \multirow{2}{*}{$\begin{array}{c}\text { Tingkat peduli masa depan } \\
\text { dimensi pengembangan potensi }\end{array}$} & \multicolumn{2}{|c|}{ Lansia peserta BKL } & \multicolumn{2}{c|}{ Lansia non peserta BKL } \\
\cline { 3 - 6 } & & Skor & Kategori & Skor & Kategori \\
\hline 1. & Kota Yogyakarta & 5,48 & Tinggi & 5,64 & Tinggi \\
\hline 2. & Kabupaten Bantul & 6,68 & Tinggi & 6,88 & Tinggi \\
\hline 3. & Kabupaten Sleman & 7,44 & Tinggi & 5,64 & Tinggi \\
\hline 4. & Kabupaten Kulonprogo & 6,60 & Tinggi & 5,80 & Tinggi \\
\hline 5. & Kabupaten Gunungkidul & 6,12 & Tinggi & 5,80 & Tinggi \\
\hline & Jumlah (DIY) & 6,46 & Tinggi & 5,95 & Tinggi \\
\hline
\end{tabular}

Sumber: data primer, 2014

\section{Tingkat Peduli Masa Depan Lansia di Daerah Istimewa Yogyakarta}

Tingkat peduli masa depan lansia di Daerah Istimewa Yogyakarta dilihat dari 5 (lima) dimensi yaitu dimensi fisik, psikologis, mental spiritual, sosial kemasyarakatan dan pengembangan potensi berada pada tingkat kategori tinggi, baik untuk lansia peserta BKL maupun non peserta BKL. Hal ini dimungkinkan karena beberapa hal, antara lain:

1. Umur lansia kebanyakan berada pada kisaran 60-64 tahun sehingga lansia dimungkinkan memiliki kepedulian tinggi terhadap kondisi fisik, psikologis, mental spiritual, sosial kemasyarakatan dan pengembangan potensi.

2. Banyaknya lansia berstatus kawin memungkinkan lansia masih dapat bertukar pikiran dan saling berbagi dengan pasangan, sehingga lansia dimungkinkan memiliki kepedulian tinggi terhadap kondisi fisik, psikologis, mental spiritual, sosial kemasyarakatan dan pengembangan potensi.

3. Lansia sebagian besar bekerja sebagai petani, memungkinkan lansia untuk beraktivitas sehingga lansia dimungkinkan memiliki kepedulian tinggi terhadap kondisi fisik, psikologis, mental spiritual, sosial kemasyarakatan dan pengembangan potensi.

4. Jumlah anggota rumah tangga lansia didominasi $\leq 2$ orang dan 3-4 orang, sehingga memungkinkan lansia tidak begitu terbebani dan lansia dimungkinkan memiliki kepedulian tinggi terhadap kondisi fisik, psikologis, mental spiritual, sosial kemasyarakatan dan pengembangan potensi. 
5. Kebanyakan lansia mengikuti organisasi kemasyarakatan memungkinkan lansia memiliki kepedulian tinggi terhadap kondisi fisik, psikologis, mental spiritual, sosial kemasyarakatan dan pengembangan potensi.

Tingkat peduli masa depan lansia di masing-masing kabupaten/kota di Daerah Istimewa Yogyakarta dilihat dari 5 (lima) dimensi juga berada pada tingkat kategori tinggi, kecuali Kota Yogyakarta (lansia peserta BKL) dan Kabupaten Kulonprogo (lansia non peserta $\mathrm{BKL}$ ) yang memiliki kategori sedang. Untuk Kota Yogyakarta kondisi ini tentunya perlu disikapi dengan peningkatan peran BKL dalam meningkatkan pengetahuan dan ketrampilan lansia terus dalam pengembangan, pengasuhan, perawatan, dan pemberdayaan agar dapat meningkatkan kesejahteraannya dan lebih peduli masa depannya.

\section{SIMPULAN}

1. Kondisi lansia di Daerah Istimewa Yogyakarta berdasarkan 5 (lima) dimensi sebagai berikut:

a. Tingkat peduli masa depan lansia di Daerah Istimewa Yogyakarta berdasarkan dimensi fisik termasuk kategori sedang, baik untuk lansia peserta BKL maupun lansia non peserta BKL. Hal ini juga dijumpai di semua kabupaten/kota, kecuali pada Kabupaten Gunungkidul untuk lansia peserta BKL termasuk kategori tinggi.

b. Tingkat peduli masa depan lansia di Daerah Istimewa Yogyakarta berdasarkan dimensi psikologis termasuk kategori sedang, baik untuk lansia peserta BKL maupun lansia non peserta BKL. Hal ini juga dijumpai di semua kabupaten/kota, kecuali pada Kabupaten Gunungkidul untuk lansia peserta BKL termasuk kategori tinggi.

c. Tingkat peduli masa depan lansia di Daerah Istimewa Yogyakarta berdasarkan dimensi mental spiritual termasuk kategori tinggi, baik untuk lansia peserta BKL maupun lansia non peserta BKL. Hal ini juga dijumpai di semua kabupaten/kota.

d. Tingkat peduli masa depan lansia di Daerah Istimewa Yogyakarta berdasarkan dimensi sosial kemasyarakatan termasuk kategori tinggi, baik untuk lansia peserta BKL maupun lansia non peserta BKL. Hal ini juga dijumpai di semua kabupaten/kota.

e. Tingkat peduli masa depan lansia di Daerah Istimewa Yogyakarta berdasarkan dimensi pengembangan potensi termasuk kategori tinggi, baik untuk lansia peserta BKL maupun lansia non peserta BKL. Hal ini juga dijumpai di semua kabupaten/kota.

2. Tingkat kepedulian lansia di Daerah Istimewa Yogyakarta pada masa depannya berdasarkan 5 (lima) dimensi berada pada tingkat kategori tinggi, baik untuk lansia peserta BKL maupun lansia non peserta BKL. Hal ini kemungkinan dipengaruhi kondisi lansia yang didominasi umur 60-64 tahun, banyaknya lansia berstatus kawin, lansia sebagian besar bekerja sebagai petani, jumlah anggota rumah tangga lansia didominasi $\leq 2$ orang dan 3-4 orang serta kebanyakan lansia mengikuti organisasi kemasyarakatan. Tingkat peduli masa depan lansia di masing-masing kabupaten/kota juga berada pada tingkat kategori tinggi, kecuali Kota Yogyakarta (lansia peserta BKL) dan Kabupaten Kulonprogo (lansia non peserta BKL) yang memiliki kategori sedang. 


\section{SARAN}

1. Meningkatkan kepedulian lansia pada masa depan, baik dari dimensi fisik, psikologis, mental spiritual, sosial kemasyarakatan maupun pengembangan potensi.

2. Memperkuat Bina Keluarga Lansia (BKL) di masing-masing kabupaten/kota di wilayah Daerah Istimewa Yogyakarta.

3. Meningkatkan mutu pengetahuan dan ketrampilan yang diberikan BKL agar lansia dapat meningkat kesejahteraannya dan lebih peduli masa depan.

4. Meningkatkan upaya penyediaan sarana dan prasarana dalam rangka pengembangan potensi lansia.

5. Memelihara dan memperkuat dukungan keluarga dan masyarakat terhadap kehidupan lansia.

6. Memperkuat koordinasi antar instansi dan instansi terkait dalam membina dan memberdayakan lansia di wilayahnya berdasarkan potensi yang dimiliki.

\section{UCAPAN TERIMA KASIH}

Penulis mengucapkan terima kasih kepada BKKBN Daerah Istimewa Yogyakarta yang telah membiayai penelitian ini. Peneliti juga mengucapkan terima kasih kepada ketua LPPM UNY yang telah memberikan ijin dan kesempatan bagi penulis untuk melaksanakan penelitian dengan dana hibah dari BKKBN DIY.

\section{DAFTAR PUSTAKA}

Ade S. (2012). PWRI Pelopor Lansia Peduli Tiga Generasi. Gemari Edisi 137/Tahun XIII/Juni 2012.

BKKBN. (2014). Bina Keluarga Lansia (BKL). Yogyakarta: BKKBN Provinsi Daerah Istimewa Yogyakarta.

BKKBN. (2014). Lansia Tangguh Tujuh Dimensi. Jakarta: BKKBN.

BPS. (2013). Daerah Istimewa Yogyakarta dalam Angka. Yogyakarta: BPS.

Ismayadi. (2004). Proses Menua (Aging Proses). Universitas Sumatera Utara: Program Studi Ilmu Keperawatan Fakultas Kedokteran. Diakses melalui USU digital library. Undang-Undang Republik Indonesia No. 13 Tahun 1998 tentang Kesejahteraan Lansia. 